\title{
BIOCHEMICAL OBSERVATIONS DURING INTRAVENOUS UREA THERAPY*
}

\author{
BY
}

\author{
S. J. CREWS AND S. I. DAVIDSON \\ Birmingham and Midland Eye Hospital
}

THE information in this paper accrued from studies of eight patients, out of a total of 43 previously reported (Crews and Davidson, 1961) to whom intravenous urea was administered. Acetazolamide was not given to any of the patients reported in this paper. Five patients with acute closed-angle glaucoma, two with phacolytic glaucoma, and one with a secondary glaucoma associated with an intumescent cataract are reported.

\section{Methods}

Intravenous urea was administered in the form of the commercial preparation "Urevert", which is supplied as a unit consisting of one bottle containing $90 \mathrm{~g}$. sterile lyophilized urea and one bottle containing $210 \mathrm{ml} .10$ per cent. invert sugar in water. This, when reconstituted, provides a 30 per cent. urea solution for intravenous use.

Intra-ocular pressures and venous blood samples were taken before infusion, at the end of infusion, and at hourly intervals for 4 hours. The plasma urea, osmolarity, sodium, and chloride were estimated. Urine samples were collected over the same period; total volume and specific gravity were recorded and the urea, sodium, and chloride outputs were estimated. The results are illustrated in Figs 1 and 2 (overleaf).

Urea was estimated in both blood and aqueous by the urease nezzlerization methods; sodium on the flame photometer; chloride by the Schales and Schales method; and osmolarity on the Fiske osmometer.

It was not possible to control the fluid intake before administration of urea, as all these patients were admitted as emergencies.

\section{Results}

Figs 1 and 2 permit the following observations (overleaf):

(1) The initial fall in intra-ocular pressure occurred simultaneously with the rise in plasma urea and osmolarity, though the tension continued to fall after the maximum blood level of urea and osmolarity had been reached.

(2) The change in osmolarity can be largely accounted for by the intravenous infusion of urea and invert sugar. In the commercial preparation used

* Received for publication October 25, 1961. 

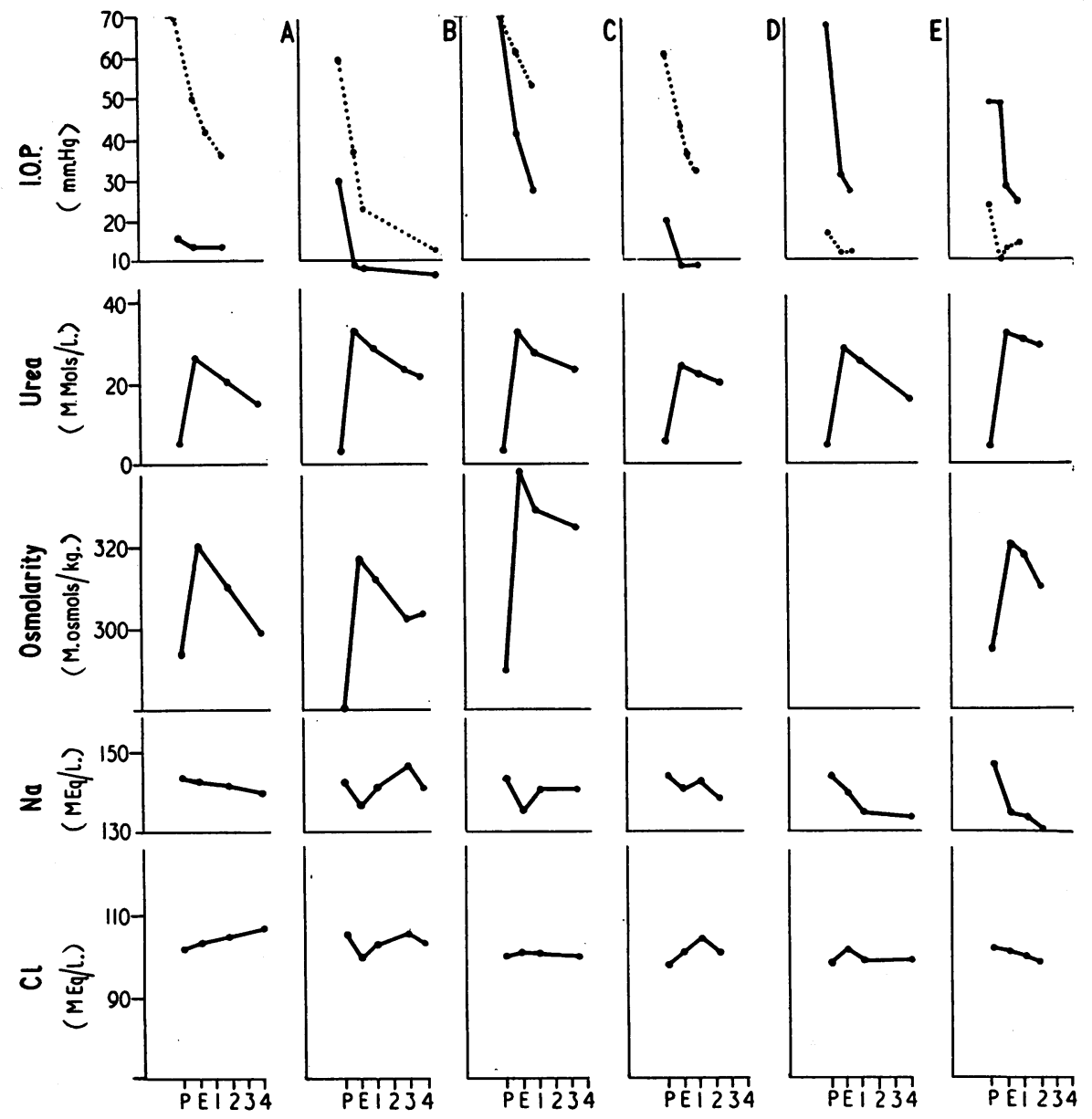

HOURS $\rightarrow$
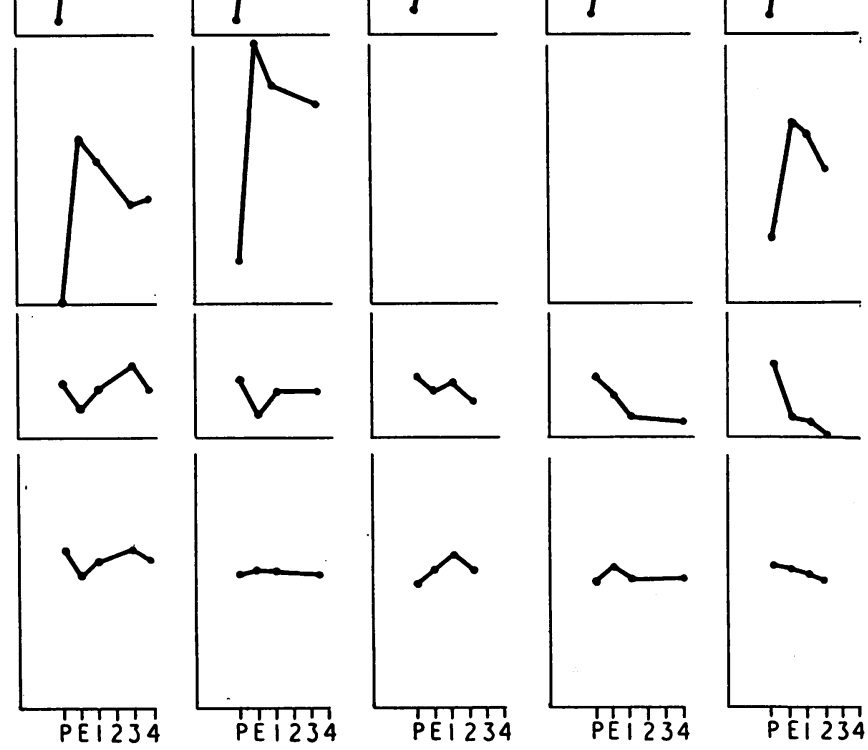

$P=$ Preinfusion $E=$ End of infusion

Fig. 1.-Biochemical observations of plasma in six patients.

In the curves for intra-ocular pressure the continuous line indicates the right eye and the interrupted line the left eye. In Cases $\mathrm{D}$ and $\mathrm{E}$ osmolarity estimations were not possible. In Case $\mathrm{C}$ the eye showing the poor response was one of absolute glaucoma.

("Urevert"), the osmotic effect of the invert sugar is calculated to be onetenth that of the urea.

(3) Initial plasma sodium values were remarkably constant, though similar plasma chloride values were slightly more variable, but in all cases these were within normal limits indicating no significant salt imbalance. Since the majority of patients had fasted and/or vomited before admission, some initial salt imbalance might be expected.

During infusion the plasma sodium level fell in every case, but the chloride levels showed no consistent change. After infusion four of the six cases 


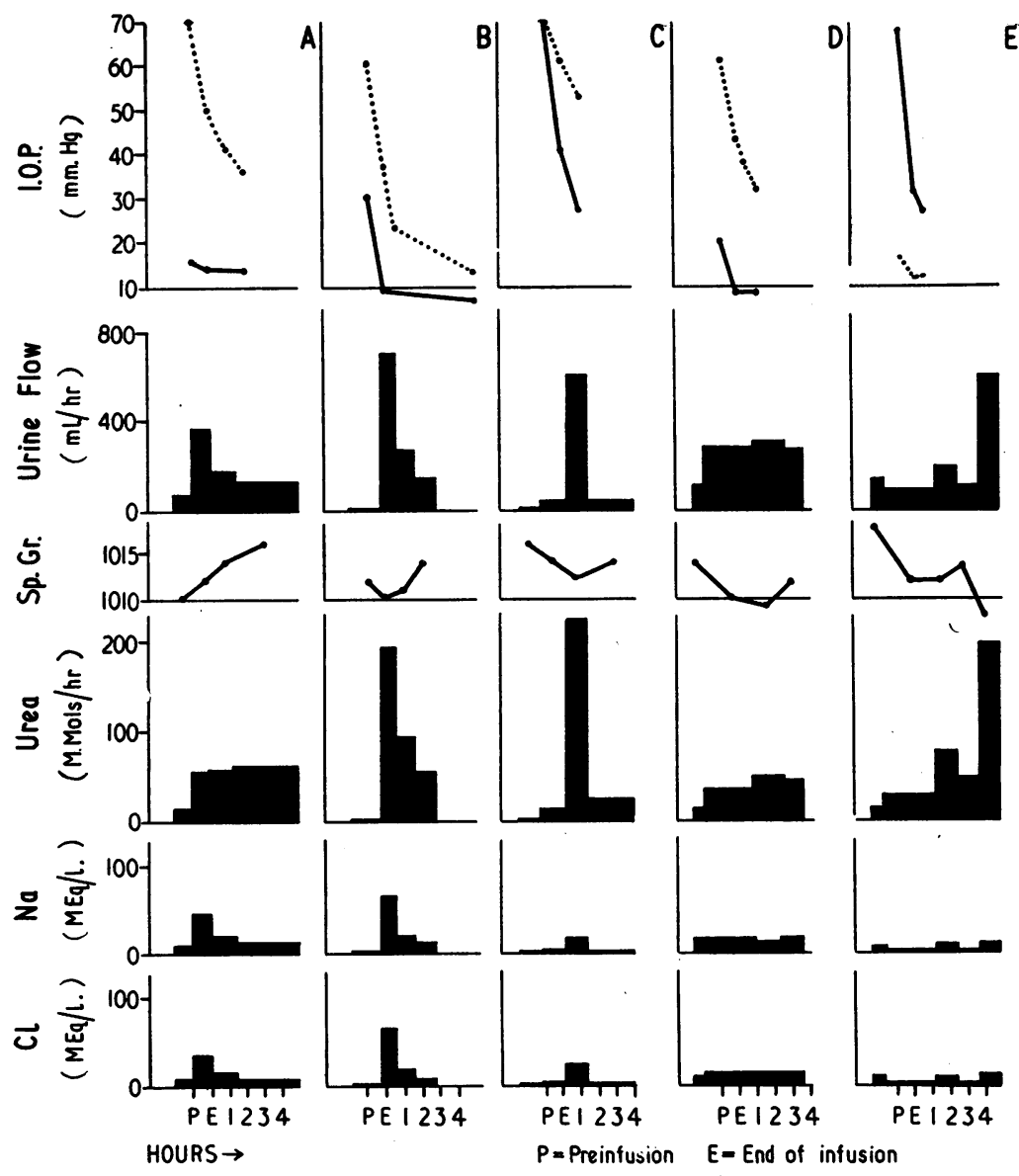

FIG. 2.-Biochemical observations of urine in five patients. Continuous and interrupted lines have same.significance as in Fig. 1. Case F (see Fig. 1) was not studied as urine was not obtained.

showed a continued fall of plasma sodium, and in the remaining two cases the sodium level rose again. The chloride levels varied considerably in relation to the sodium and showed no consistent pattern.

(4) The diuresis varied markedly in time and quantity as it did clinically in the other 35 cases of the series.

There was an increased output of urea, sodium, and chloride associated with the water diuresis, but this bore no close relation to the fall in intraocular pressure.

Aqueous samples were taken in three cases (see Table, overleaf):

Case F, Acute Closed-angle Glaucoma. Simultaneous blood and aqueous samples were taken 2 hours after the intravenous infusion of urea, and urea and sodium were estimated 
TABLE

\begin{tabular}{c|c|c|c|c|c}
\hline \multirow{2}{*}{ Case } & \multicolumn{3}{|c|}{ Urea (mg. per cent.) } & \multicolumn{2}{c}{ Sodium (mg. per cent.) } \\
\cline { 2 - 5 } & Plasma (water) & Aqueous & $\mathbf{R}_{\mathrm{aq}}{ }^{*}$ & Aqueous & $\mathbf{R}_{\mathrm{aq}}$ \\
\hline $\mathrm{F}$ & 188.7 & 125 & 0.66 & 322 & 1.01 \\
\hline $\mathrm{G}$ & 56.2 & $41 \cdot 7$ & 0.74 & & \\
\hline $\mathrm{H}$ & $109 \cdot 5$ & 93.3 & 0.86 & & \\
\hline
\end{tabular}

* $\mathbf{R}_{\mathrm{aq}}=\frac{\text { aqueous concentration }}{\text { corrected plasma concentration }}$

(Table). By this time the intra-ocular pressure had fallen to $24 \mathrm{~mm}$. $\mathrm{Hg}$ (Schiötz) from an initial level of $50 \mathrm{~mm} . \mathrm{Hg}$, and the plasma urea, osmolarity, and sodium were falling. The corrected relative concentration aqueous/plasma $\left(R_{a q}\right)$ for urea is 0.66 and that for sodium 1.01. This figure for urea is thus only slightly below the normal range of 0.7 to 0.8 estimated by Davson (1953). The original value in the normal human eye was reported by Moore, Scheie, and Adler (1942) as 0.83.

Case G, Phacolytic Glaucoma. The initial tension was $81.7 \mathrm{~mm}$. $\mathrm{Hg}$; blood and aqueous samples were taken 4 hours after infusion, by which time the intra-ocular pressure had risen to $45 \mathrm{~mm}$. $\mathrm{Hg}$, following a fall to $28.5 \mathrm{~mm}$. $\mathrm{Hg}$. The corrected relative concentration $\left(\mathbf{R}_{\mathrm{aq}}\right)$ for urea is $\mathbf{0 \cdot 7 4}$.

Case H, Phacolytic Glaucoma. Blood and aqueous samples were taken 80 minutes after the infusion ceased, by which time the tension had fallen from 81.7 to $33 \mathrm{~mm}$. $\mathrm{Hg}$, having reduced to as low as $28.4 \mathrm{~mm}$. $\mathrm{Hg}$ in the interim. The corrected relative concentration $\left(R_{\mathrm{aq}}\right)$ for urea is $\mathbf{0 . 8 6}$.

It should be noted that the aqueous samples were taken from one case of acute closed-angle glaucoma and two cases of phacolytic glaucoma, and that the permeability of the aqueous barrier may differ in the two conditions.

\section{Comment}

Though the numbers concerned are not significant, it may be said that these observations support the concept of the osmotic action of intravenous urea upon the eye, an action which is not directly related to its diuretic effect.

We are grateful to the surgeons of the Birmingham and Midland Eye Hospital for allowing us. to treat their patients, and to the Research Department for help in the estimations.

\section{REFERENCES}

Crews, S. J., and Davidson, S. I. (1961). Brit. J. Ophthal., 45, 769.

Davson, H., and MatcheTt, P. A. (1953). J. Physiol. (Lond.), 122, 11.

MOORE, E., SCheIE, H. G., and AdLeR, F. H. (1942). Arch. Ophthal. (Chicago), $27,317$. 